\title{
Power Consumption Comparison of Model Vibratory Unit in Power Supply System with and without Inverter for Frequency Setting of $50 \mathrm{~Hz}$
}

\author{
Eugeniusz Ziółkowskia,*, Mateusz Skrzyńskia \\ ${ }^{a}$ AGH University of Science and Technology, Faculty of Foundry Engineering, Reymonta 23, 30-059 Krakow, Poland \\ *e-mail: ez@agh.edu.pl
}

Received: 31 May 2017/Accepted: 7 July 2017/Published online: 28 July 2017

This article is published with open access at AGH University of Science and Technology Press

\section{Abstract}

The article presents the instantaneous voltage and current values recorded in the power-supply system of a vibratory unit directly from the power grid or through an inverter for a frequency setting of $50 \mathrm{~Hz}$. The obtained measurement data was used to perform digital signal processing algorithms, calculations of effective voltages, currents, power (active, reactive, and apparent), and power factor $\operatorname{tg} \varphi$. The results of the calculations were used to compare the two power systems examined.

Keywords:

model of vibratory unit, selected energy parameters

\section{INTRODUCTION}

In machines for the mechanical regeneration of used molding mass, vibratory units driven by electric motors are commonly used. An example of such a regenerator is described in publications [1-3]. To study the influence of the selected structural and operational parameters on the efficiency of mechanical regeneration of the used molding mass, a model station was constructed (the view of which is shown in Figure 1a). The model vibratory unit is driven by two electric motors, with the parameters given in Table 1 .

The article presents the instantaneous voltage and current values recorded in the power supply system of the vibratory unit directly from the power grid or through an inverter [5] for a frequency setting of $50 \mathrm{~Hz}$. Measurements were made with the use of the original recorder of instantaneous voltages and currents, whose technical characteristics were presented in works $[6,7]$, among others. Calculations of the selected energy parameters [8-12] were carried out using the author's computer program. A view of the measurement system is shown in Figure 1b.

Table 1

Parameters of MVE 400/3 electric motor used in model vibratory unit [4]

\begin{tabular}{cc}
\hline Type of electric motor & MVE 400/3 \\
\hline Producer & OLI WAMGROUP \\
\hline Voltage supply & $\Delta 230 \mathrm{~V} /$ Y 400 V \\
\hline Frequency & $50 \mathrm{~Hz}$ \\
\hline Power & $0,3 \mathrm{~kW}$ \\
\hline Maximum current & $\Delta 1.0 \mathrm{~A} / \mathrm{Y} 0.58 \mathrm{~A}$ \\
\hline Power coefficient $\cos \varphi$ & 0.88 \\
\hline Speed & $3000 \mathrm{rpm}$ \\
\hline
\end{tabular}

a)

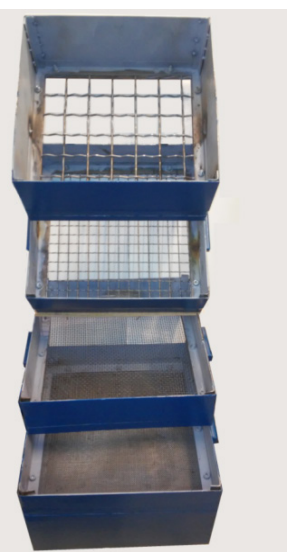

b)

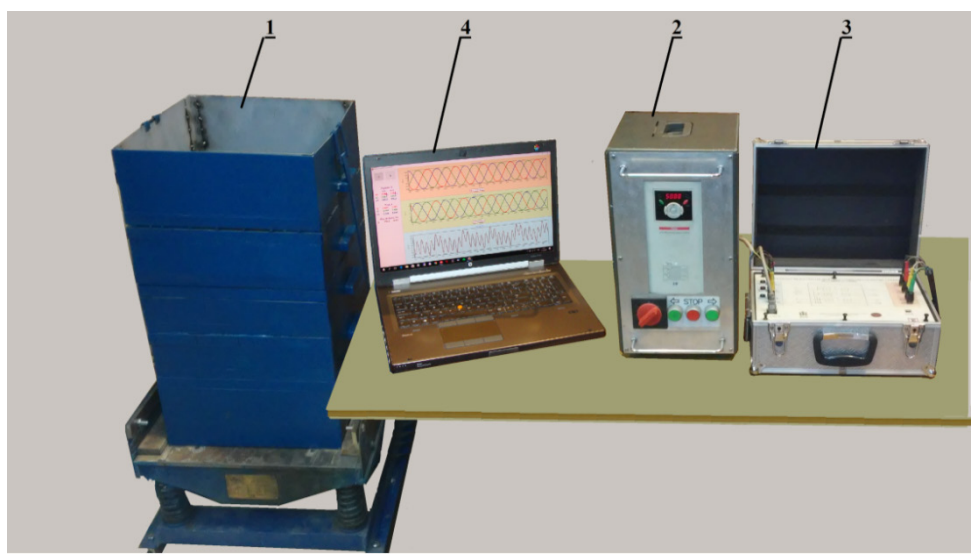

Fig. 1. View of: a) model vibratory unit; b) research system: 1 - model vibratory unit; 2 - inverter; 3 - instantaneous voltage- and current-value recorder; 4 - computer with software for recorder 


\section{MEASUREMENTS OF SELECTED PARAMETERS POWERED DIRECTLY FROM ENERGY NETWORK OF MODEL VIBRATORY UNIT}

In order to record the instantaneous voltage and current values, the recorder was connected between the threephase power grid $(400 \mathrm{~V}, 50 \mathrm{~Hz})$ and the model vibration test (Fig. 2). All results presented in this article refer to the nominal loading of waste molded mass $(21 \mathrm{~kg})$ in a model vibratory unit. Figure 3 shows a view of a computer program window that supports an instantaneous value recorder, containing graphs of voltage and current changes in each phase of the power supply.

The set of instantaneous values was used to determine the effective voltage and current values after switching on the power supply (Fig. 4) as well as the changes in the active, reactive, and apparent power values as well as the coefficient power $\operatorname{tg} \varphi$ values (Fig. 5).

From the graphs in Figures 3-5, it can be seen that the transient state persist at about $0.5 \mathrm{~s}$.

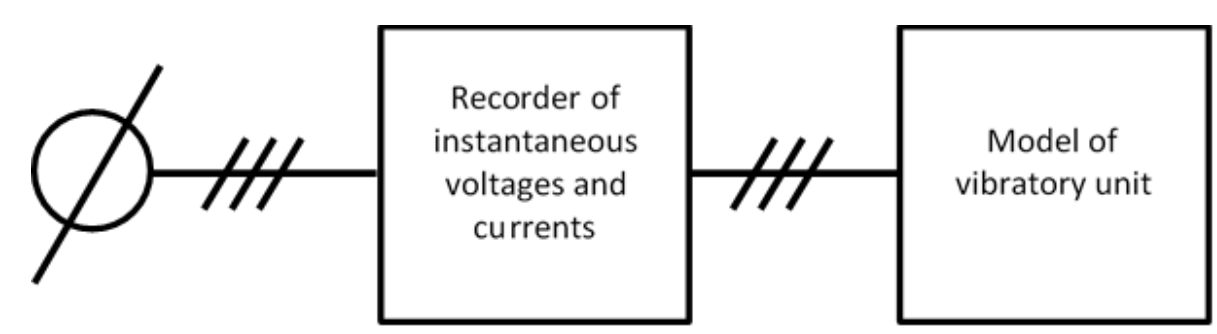

Fig. 2. Diagram of recording system of instantaneous voltage and current values in vibration unit supplied directly from three-phase power grid $(50 \mathrm{~Hz})$

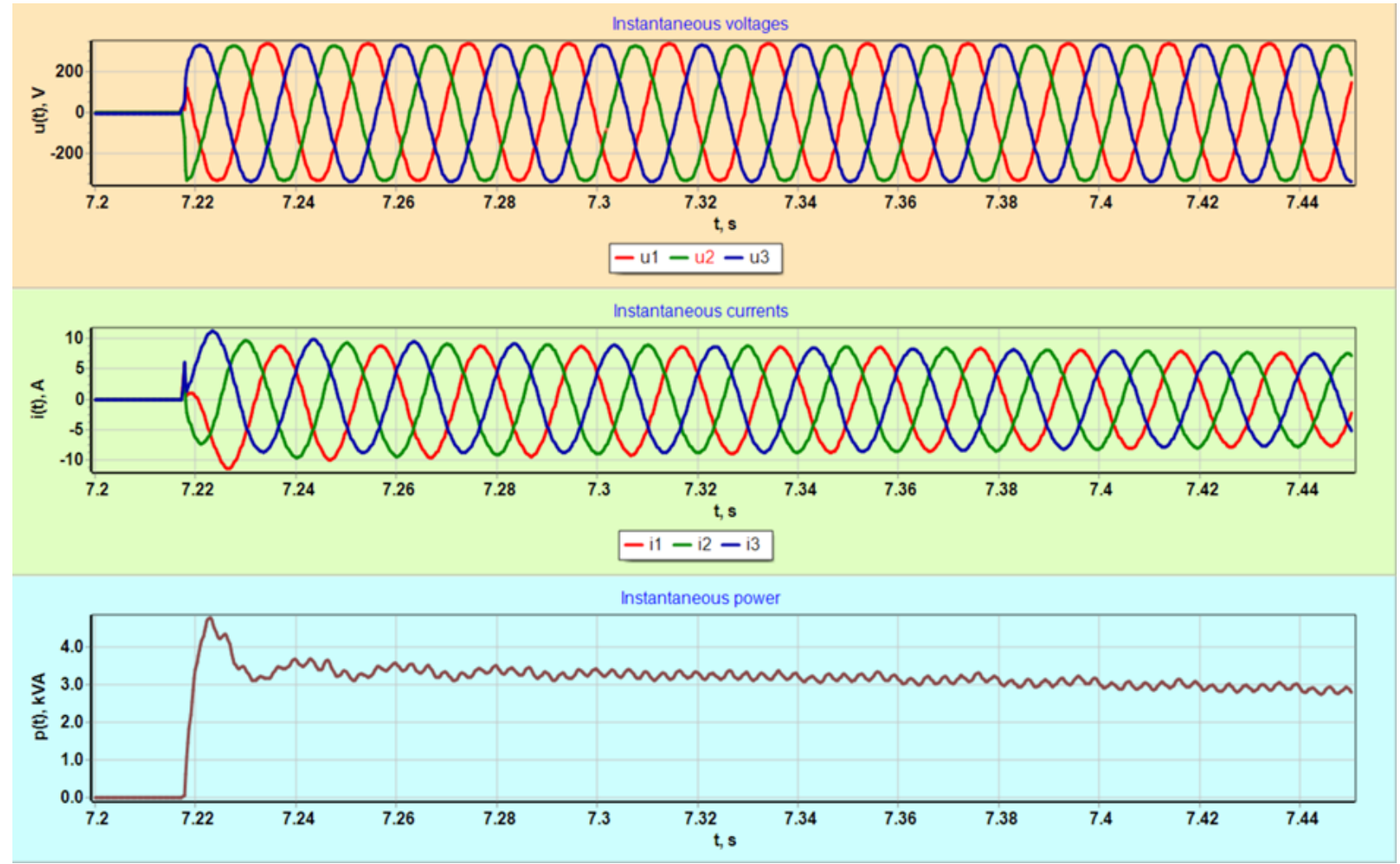

Fig. 3. Program window with graphs of instantaneous voltages and currents in model vibratory unit supplied directly from energy network 


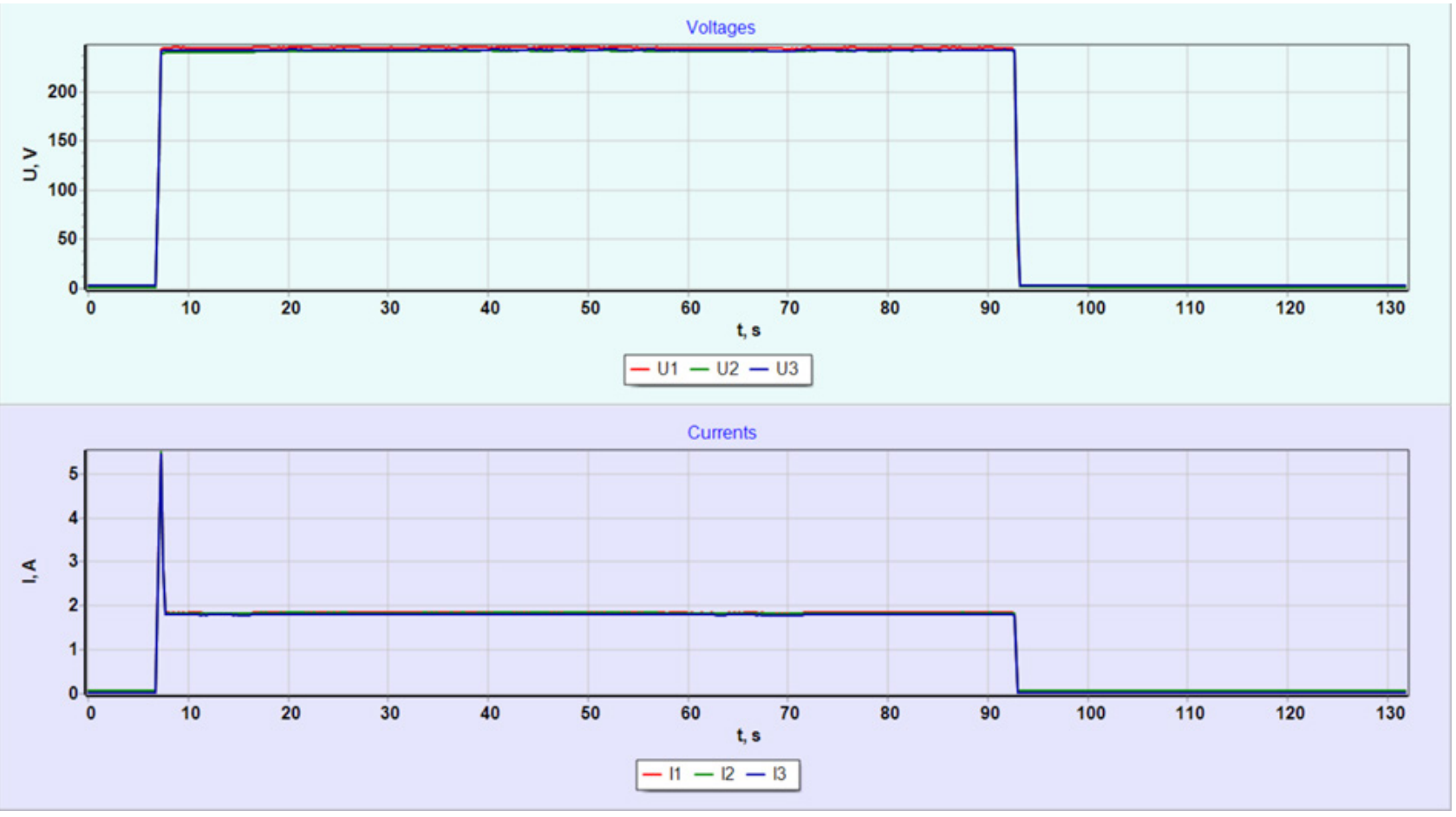

Fig. 4. Graph of changes of effective voltage and current values in model vibratory unit supplied directly from power grid

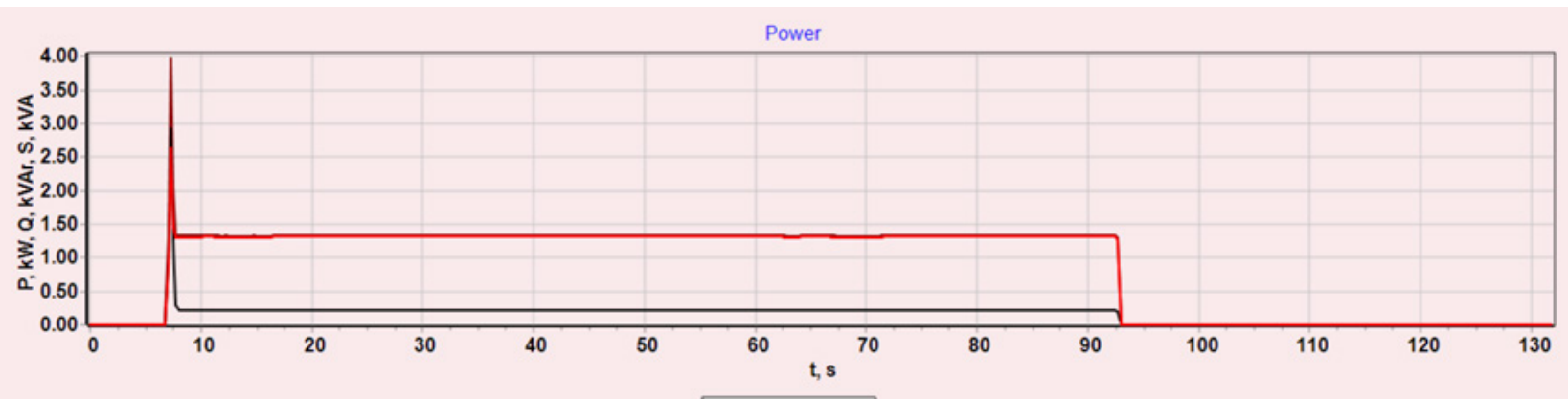

$-S-P-Q$

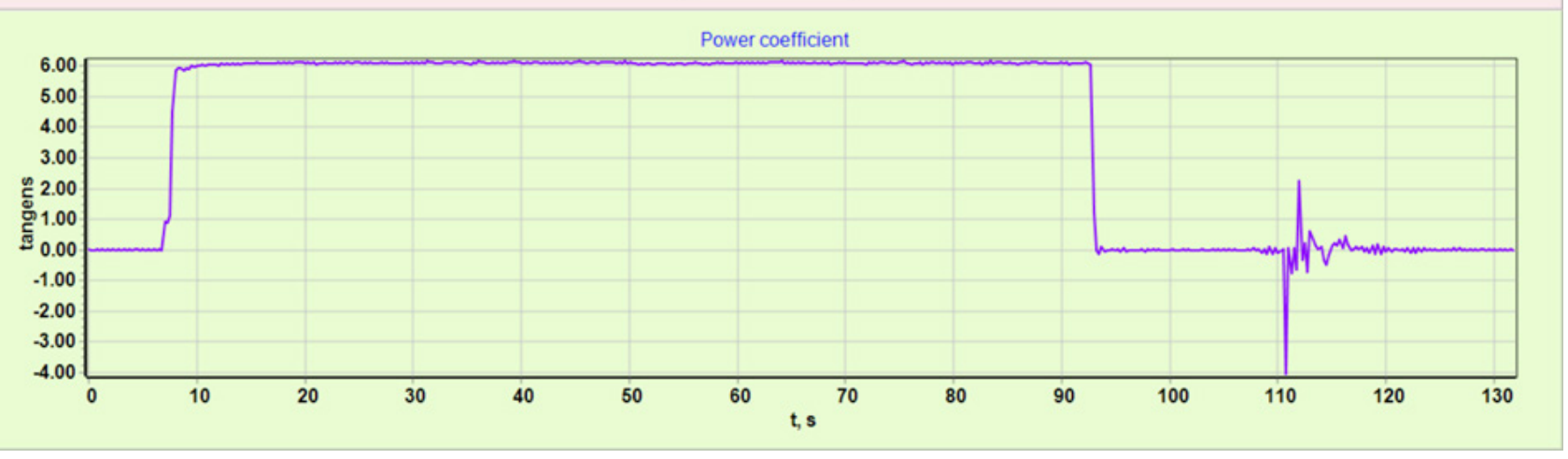

Fig. 5. Graph of changes in active, reactive, and apparent power values as well as coefficient power tg $\varphi$ in model vibratory unit supplied directly from energy network 
Table 2 lists the values of the currents and power parameters in the transient and steady states.

Table 2

Summary of maximum instantaneous and effective values in system of model vibratory unit supplied directly from power grid

\begin{tabular}{ccc}
\hline Parameter & $\begin{array}{c}\text { Transient } \\
\text { state }\end{array}$ & $\begin{array}{c}\text { Steady } \\
\text { state }\end{array}$ \\
\hline Instantaneous current value, A & 11.3 & 2.5 \\
\hline Effective current, A & 5.5 & 1.8 \\
\hline Instantaneous power value, kVA & 4.7 & 0.29 \\
\hline Active power, $\mathrm{kW}$ & 2.93 & 0.23 \\
\hline Reactive power, $\mathrm{kVAr}$ & 2.63 & 1.30 \\
\hline Apparent power, $\mathrm{kVA}$ & 3.96 & 1.33 \\
\hline Power factor, tg $\varphi$ & \multicolumn{2}{c}{6.2} \\
\hline
\end{tabular}

From an analysis of the data in Table 2, the instantaneous phase current value at the time of switching on the power was 4.5 times greater than the current value at this phase in the steady state of the model vibratory unit operation. The maximum effective value of the phase current in the transient state was 3 times higher than the effective value of the phase current in the steady state. The instantaneous power of the transient state was more than 16 times higher than the instantaneous power of the steady state. The power-supply system of the two motors in the vibratory unit was characterized by a power factor of $\operatorname{tg} \varphi=6.2(\cos \varphi=0.16)$, which means the reactive power compensation is incorrect.

\section{MEASUREMENTS}

\section{IN MODEL VIBRATORY UNIT POWER SUPPLY WITH INVERTER FOR FREQUENCY SETTING OF $50 \mathrm{~Hz}$}

A three-phase LS Industrial Systems [5] inverter (SV055iG5A-4) with maximum power of $5.5 \mathrm{~kW}$ and maximum frequency of $400 \mathrm{~Hz}$ was used in the power supply of the model vibratory unit. The tests were performed for the $50 \mathrm{~Hz}$ frequency supply voltage made according to the diagram shown in Figure 6. This allowed us to collect information on the selected power parameters between the inverter and drive motors of the model vibratory unit.

For the recorded changes in the instantaneous voltage, current, and power values (Fig. 7), the effective values of voltages and currents (Fig. 8) have been calculated along with the active, reactive, and apparent power as well as the power factor $\operatorname{tg} \varphi$ (Fig. 9).

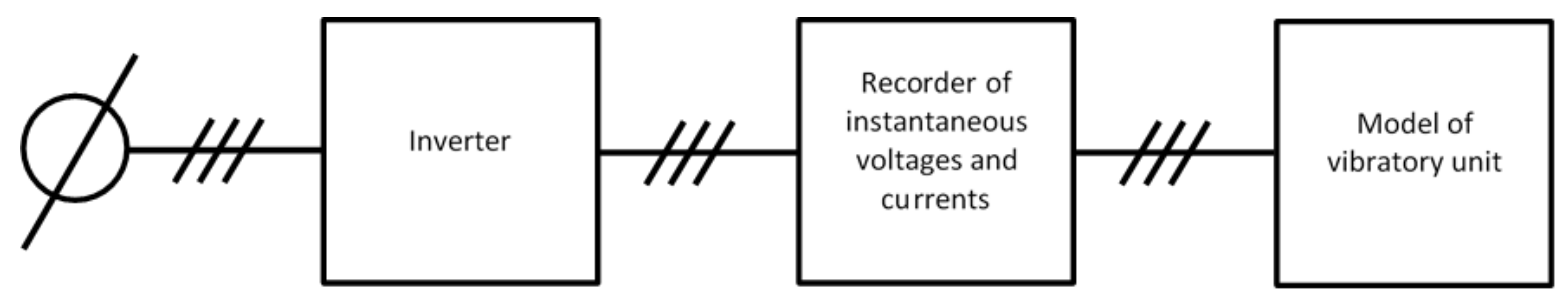

Fig. 6. Diagram of recording system of instantaneous voltage and current values between inverter and model vibratory unit

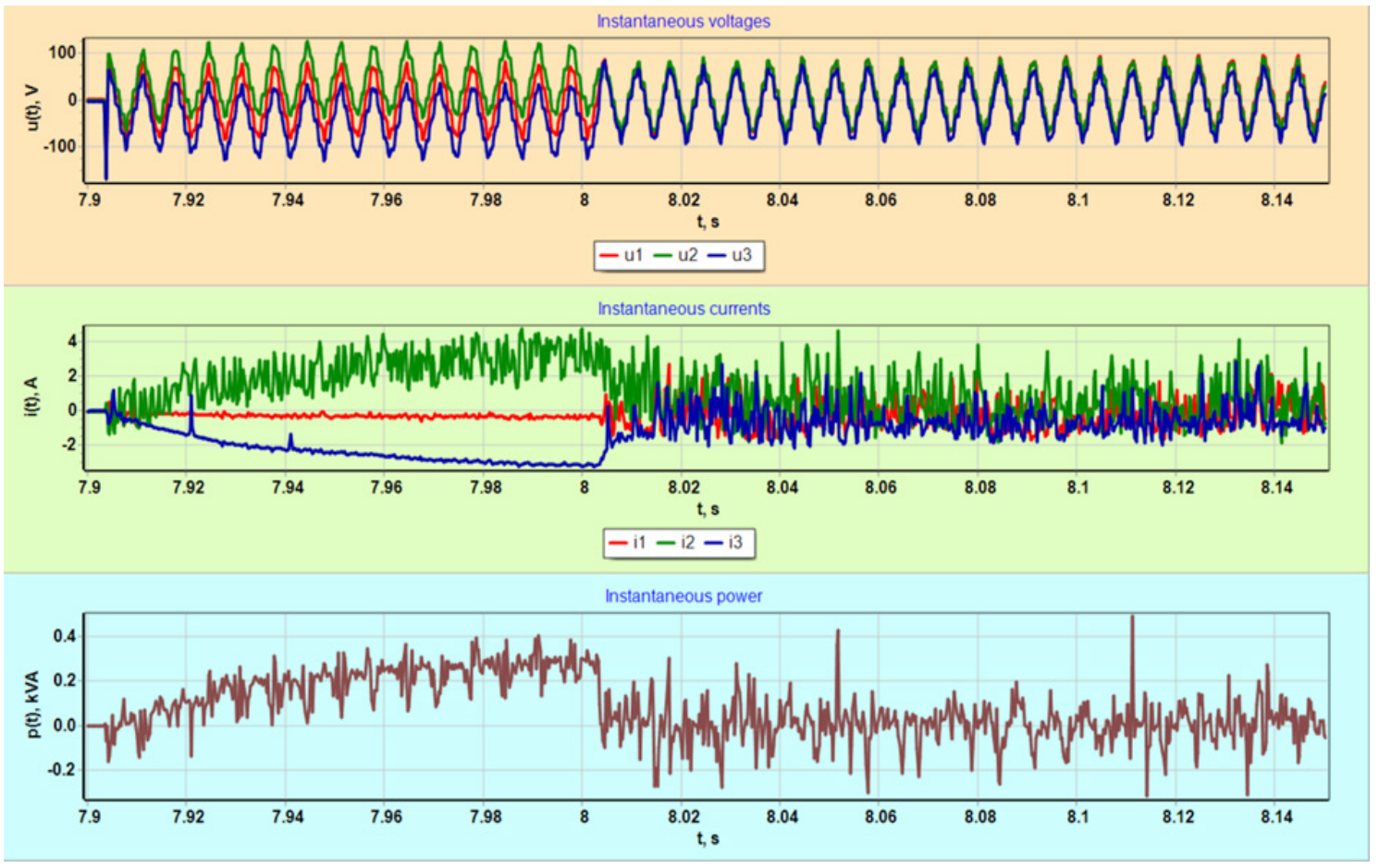

Fig. 7. Graphs of instantaneous voltages, currents, and power in the system according to Figure 6 (frequency inverter setting is $50 \mathrm{~Hz}$ ) 
As can be seen from the graphs in Figure 7, the shapes of the phase currents in both the transient and steady states deviate significantly from the sinusoidal ones. The effective current value in the transient state is more than
$30 \%$ higher than the effective current value in the steady state (Fig. 8). Power factor $\operatorname{tg} \varphi$ is equal to approximately 6.0 in the steady state, which means the compensation of reactive power is incorrect (Fig. 9).
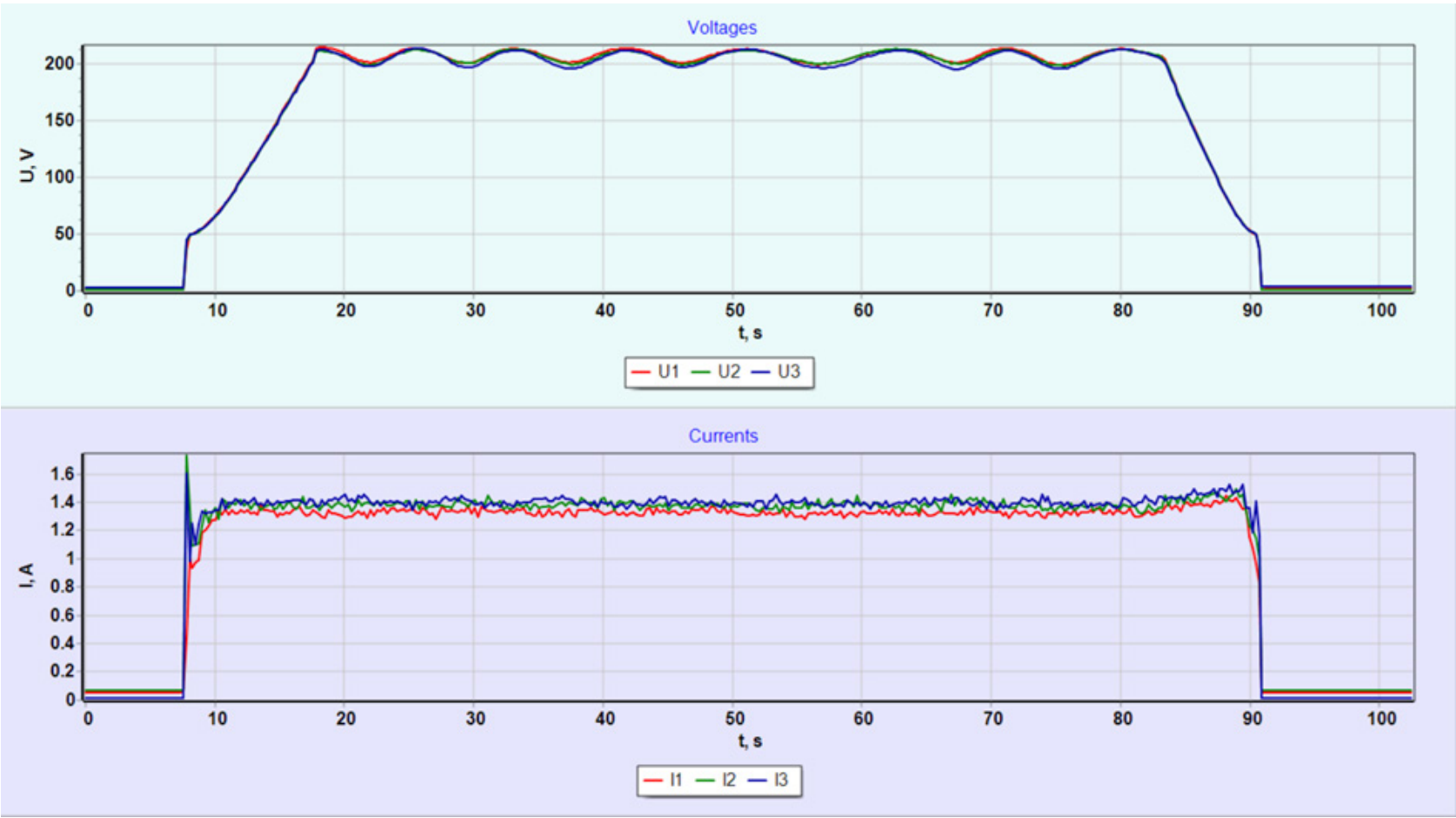

Fig. 8. Graphs of effective voltages and currents in system according to Figure 6 (frequency inverter setting is $50 \mathrm{~Hz}$ )

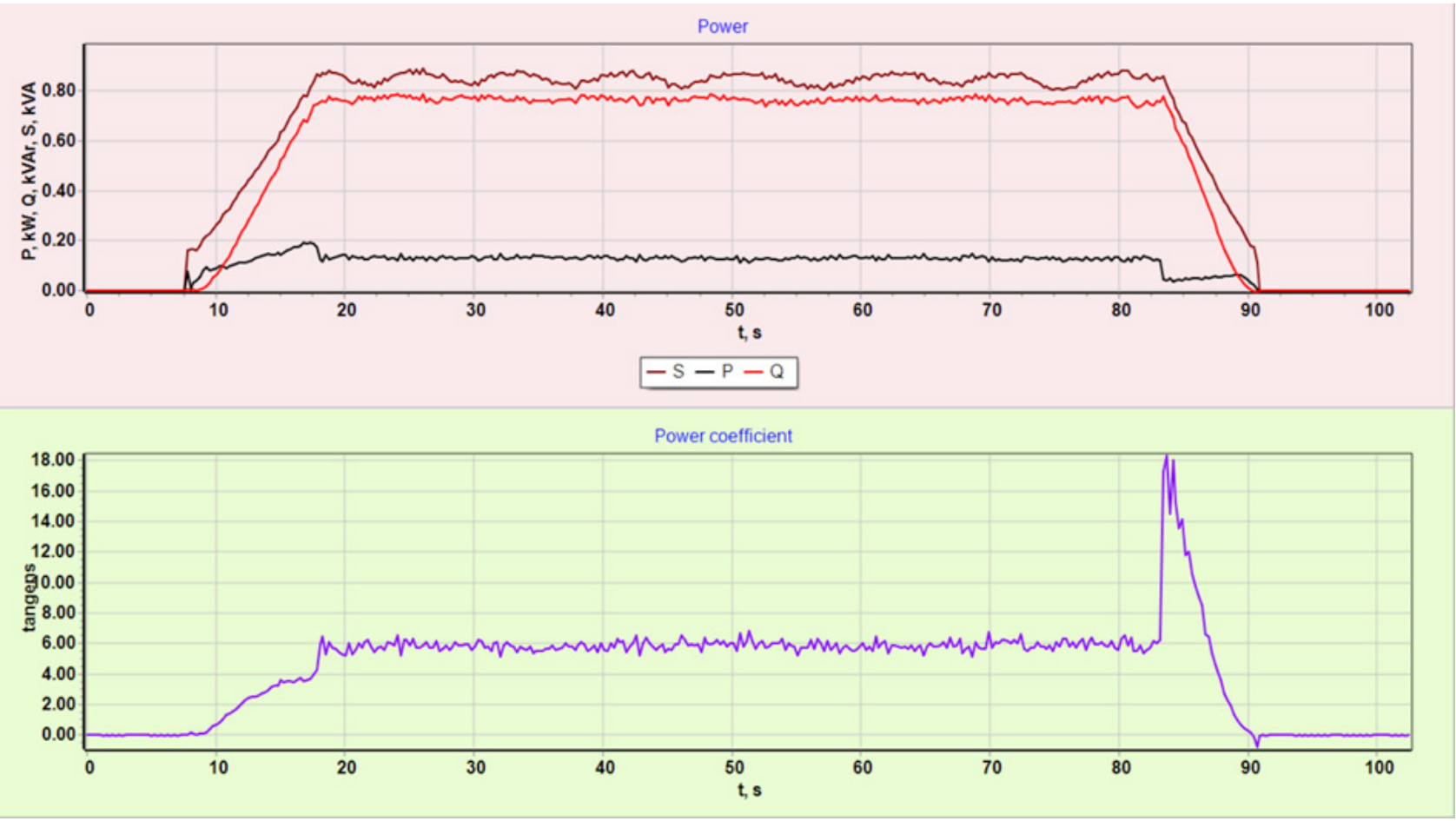

Fig. 9. Graphs of active, reactive, and apparent power as well as power factor $\operatorname{tg} \varphi$ in system according to Figure 6 (frequency inverter setting is $50 \mathrm{~Hz}$ ) 


\section{COMPARISON OF MEASUREMENTS AND CALCULATIONS RESULTS}

Table 3 summarizes the measurement and calculation results of the selected power parameters for the model vibratory unit supplied directly from the power grid and through the inverter (frequency setting is $50 \mathrm{~Hz}$ ).

Table 3

A summary of the selected energy parameter values in the model vibratory unit supplied directly from the energy network or while using an inverter (frequency setting is $50 \mathrm{~Hz}$ )

\begin{tabular}{|c|c|c|}
\hline \multirow{2}{*}{$\begin{array}{c}\text { Parameter } \\
\text { (steady state) }\end{array}$} & \multicolumn{2}{|c|}{ Power supply } \\
\hline & $\begin{array}{c}\text { directly from } \\
\text { energy network }\end{array}$ & using inverter \\
\hline Effective voltage, $\mathrm{V}$ & 243.0 & 210.0 \\
\hline Effective current, A & 1.8 & 1.4 \\
\hline Active power, kW & 0.23 & 0.15 \\
\hline Reactive power, kVAr & 1.30 & 0.76 \\
\hline Apparent powerf, kVA & 1.43 & 0.90 \\
\hline Power factor, $\operatorname{tg} \varphi$ & 6.0 & 6.0 \\
\hline
\end{tabular}

The power consumption of the model vibratory drive for the standard inverter parameter settings (frequency equal $50 \mathrm{~Hz}$ ) represents approximately $63 \%$ of the power consumption when supplied directly from the energy network. This is the result of the smaller values in the effective voltages and currents. The power factor $\operatorname{tg} \varphi$ is a constant value only. In the steady state, the use of the inverter in the power supply causes relatively small deformations from the sinusoid for the voltages and a very high level of harmonic currents. It also enables the soft start of the motors after power up as well as their smooth braking. In this power system, there are significantly smaller peaks in the steady state than in the case of direct supply from the power grid.

\section{CONCLUSIONS}

The performed measurements and calculations of the selected energy parameters in two variants of the power-supply system of the model vibratory unit (directly from an energy network or using an inverter for a frequency setting of $50 \mathrm{~Hz}$ ) allow us to compare the power consumption and effective voltage and current values in the transient or steady states. Using the inverter with standard setting parameters for a frequency of $50 \mathrm{~Hz}$ causes lower power consumption by motors compared to the supply from an energy network, as well as lower effective voltage and current values and very large deviations in the currents from the sinusoid.

\section{Acknowledgements}

This work was elaborated under research and development study no. 11.11.170.318, task 6.

\section{REFERENCES}

[1] Dańko J., Kamińska J., Skrzyński M. (2013). Reclamation of spent moulding sands with inorganic binders in the vibratory reclaimer REGMAS. Archives of Metallurgy and Materials, 3(58), 993-996.

[2] Polzin H., Nitsch U., Tilch W., Flemming,E. (1997). Regenerierung anorganisch gebundener Altsande mit einer mechanisch arbeitender Pilotanlage. Gieserei-Praxis, 23/24, 500-507.

[3] Boenisch D. (1990). Reclamation of spent used sands containing bentonite. Guidelines for an economical leading to minimized waste. Giesserei, 77(19), 602-609.

[4] Industrial vibrators. Retrieved from http://www.wamgroup. com/en-GB/corporate/Family/405/Industrial-Vibrators (accesed 4.05.2017).

[5] Variable frequency drives. Retrieved from http://www.lsis. com/usa (accesed 5.05.2017).

[6] Ziółkowski E. (2010). Monitoring of the supply system of electrical foundry equipment. Archives of Foundry Engineering, 10(2), 169-172.

[7] Ziółkowski E., Smyksy K., Bień A. (2016). Monitoring power supply systems of electric foundry devices using recorder of voltage and current instantaneous values. In Górny M., Grabowska B., Gurgul D. (Ed.), Nauka i technika w inżynierii procesów odlewniczych. Kraków: Akapit, 101-106.

[8] IEEE standard definitions for the measurement of electric power quantities under sinusoidal, nonsinusoidal, balanced and unbalanced conditions. IEEE, 1459-2010.

[9] Miller J.E. (Ed.) (1982). Reactive power control in electric systems. New York: John Willey \& Sons.

[10] Abur A., Expósito A.G. (2004). Power System State Estimation: Theory and Implementation. CRC Press.

[11] Zieliński T.P. (2007). Digital signal processing: from theory to applications. (2nd ed.). Warsaw: Communication and Transport Publisher.

[12] Czarnecki L.S., Halley P.M. (2014). Unbalanced power in fourwire systems and its reactive compensation. IEEE Transactions on Power Delivery, 30(1), 53-63. 